\title{
Response of Cortisol Metabolites in the Insulin Tolerance Test and Synacthen Tests
}

\author{
K. SIMUNKOVA ${ }^{1,2}$, M. DUSKOVA ${ }^{2}$, M. KOSAK ${ }^{1}$, M. KRSEK ${ }^{1}$, V. HANA ${ }^{1}$, M. HILL ${ }^{2}$, \\ H. JANDIKOVA ${ }^{2}$, H. POSPISILOVA ${ }^{2}$, M. SRAMKOVA ${ }^{2}$, E. BIFULCO ${ }^{3}$, L. STARKA ${ }^{2}$ \\ ${ }^{1}$ Third Department of Medicine, General University Hospital and First Faculty of Medicine, Charles \\ University, Prague, Czech Republic, ${ }^{2}$ Institute of Endocrinology, Prague, Czech Republic, \\ ${ }^{3}$ Department of Clinical Science, University of Bergen, Bergen, Norway
}

Received July 14, 2015

Accepted July 28, 2015

\section{Summary}

Determination of response of cortisol and its metabolites to different stimuli may be important for adrenal gland disorders. To date, only one metabolite, cortisone, has been followed in stimulation tests of the adrenal gland. We aimed to describe a response of cortisol metabolites to the standard short Synacthen test (HDST), insulin tolerance test (ITT), low dose Synacthen test (LDST) and medium dose Synacthen test (MDST). Sixty healthy subjects were investigated: 30 men and 30 women. Plasma for measurements of cortisol and its metabolites was obtained before and 30th and 60th min after Synacthen and insulin administration. The cut-off $500 \mathrm{nmol} / \mathrm{l}$ of cortisol was reached after stimulation in all of tests, the maximal stimulation level was reached in 60th min in all of the tests except for LDST. The response of cortisol and its metabolites at 30th and 60th min strongly correlated in all of the tests except for LDST. Cortisol and its metabolites increased after stimulation; in contrast, cortisone and its metabolites decreased. We showed that the response of the cortisol metabolites during the Synacthen tests and ITT well correlated, and the MDST showed similar response compared to HDST. The decrease in cortisone metabolites may correspond to the regeneration of cortisol from cortisone in response to stimulation test.

\section{Key words}

Synacthen test $\bullet$ Cortisol $\bullet$ Cortisone $\bullet$ Insulin tolerance test

\section{Corresponding author}

K. Simunkova, Third department of Medicine, General University Hospital and First Faculty of Medicine, Charles University, U Nemocnice 1, 12808 Prague 2, Czech Republic. E-mail: ksimunkova@gmail.com

\section{Introduction}

Cortisol is the key hormone responsible for maintaining the homeostasis in the body and for responses to every stress event. Adrenal glands are releasing cortisol under specific rhythm almost every hour with the higher amplitude of peaks in the morning and the lowest in the evening (Lightman 2014). Cortisol precursor levels are essential for the diagnostic procedure in stimulation test of adrenal disorders and response of cortisol precursors has been described (Willenberg et al. 2002). So far, only cortisone has been followed in stimulation test of adrenal gland, response of other cortisol and cortisone metabolites have not yet been described.

The critical and crucial step in cortisol metabolism is cortisol regeneration from cortisone or its conversion to cortisone by $11 \beta$-hydroxysteroid dehydrogenase 1 (11 $\beta$-HSD1). That conversion enables the recycling of cortisol and cortisone in peripheral tissues (Hughes et al. 2012, Nixon et al. 2012). $11 \beta$-hydroxysteroid dehydrogenase 2 (11 $\beta$-HSD2) inactivates cortisol in the kidney and protects mineralocorticoid receptors against cortisol excess (Dotsch et al. 2001). Cortisol and cortisone are then converted to dihydrocortisol (DHF) and dihydrocortisone, which are further reduced to tetrahydrocortisol (THF) and tetrahydrocortisone (THE). This process constitutes the main pathway. DHF may be reduced by $5 \alpha$-reductase or $5 \beta$-reductase to two isoforms THF and allo-THF. The minor pathway involves hydroxylation by $6 \beta$-hydroxylase to 6 $\beta$-hydroxycortisol (Larsen et al. 
2002). Urinary cortisol and its metabolites as well as cortisol/cortisone ratio are used to evaluate the activity of cortisol metabolising hormones in several disorders and may be used to predict cardiovascular risk in various diseases (Gomes-Santos et al. 2014).

The insulin tolerance test (ITT) has been traditionally regarded as the gold standard for evaluation of the hypothalamic-pituitary-adrenal (HPA) axis. However, the ITT has several limitations and has to be avoided in several conditions due to artificially caused hypoglycemia. Several alternative tests for the HPA axis assessment have been proposed over the years (e.g. glucagon or metyrapon test) but only the Synacthen test has demonstrated good sensitivity and specificity compared to the ITT in many studies (Hurel et al. 1996, Rasmuson et al. 1996, Abdu et al. 1999). The standard short Synacthen test is cheaper, safer and less unpleasant for patient than the ITT and assesses directly the capacity of the adrenal cortex and indirectly of HPA. We focused on the response of metabolites of cortisol to the ITT and Synacthen tests involving three different doses. The main aim was to compare the maximal response of cortisol and its metabolites to the stimulation tests and to determine whether the low dose Synacthen test (LDST, $1 \mu \mathrm{g}$ dose) results in the same level of cortisol metabolites as the standard short Synacthen test (HDST, $250 \mu \mathrm{g}$ ) and the ITT. The second aim was to investigate the response of cortisol and its metabolites to a medium dose Synacthen test (MDST, $10 \mu \mathrm{g}$ Synacthen test) and to compare the response with the responses to the other tests.

\section{Subjects and Methods}

\section{Subjects}

Sixty healthy subjects, 30 men and 30 women (age $38 \pm 10$ years (mean \pm SD), BMI $24.5 \pm 2.7 \mathrm{~kg} / \mathrm{m}^{2}$, $\mathrm{p}=0.08)$ were examined by the ITT, HDST $(250 \mu \mathrm{g})$, LDST $(1 \mu \mathrm{g})$ and MDST $(10 \mu \mathrm{g})$. The study was approved by the local Ethical Committee.

The healthy subjects did not have a medical history of steroid treatment. Women included in the study were not pregnant, were in the follicular phase of the menstrual cycle and did not use any contraceptives or their use was discontinued at least 6 weeks before the investigation. The healthy subjects signed an informed consent before entering the study, which was approved by the Ethical Committee of the Institute of Endocrinology and General University Hospital.
Performance of dynamic tests of the HPA axis

Each healthy subject underwent all 4 tests. Adrenal function was evaluated by measurement of basal and stimulated values of following the steroids cortisol, cortisone, tetrahydrocortisone (THE), tetrahydrocortisol (THF), allo THF and $6 \beta$-hydroxycortisol $(6 \beta-\mathrm{OHF})$ in plasma during the ITT, LDST, HDST, MDST.

The insulin dose was calculated according to the body weight and a dose of 0.1-0.2 IU/ $\mathrm{kg}$; of rapid acting insulin was administered intravenously and hypoglyceamia $<2.2 \mathrm{nmol} / 1$ was reached.

\section{Preparation of the dose of $1 \mu \mathrm{g}$ Synacthen for LDST}

The content of an ampoule with $250 \mu \mathrm{g} / 1 \mathrm{ml}$ ACTH (Synacthen, tetracosactide $250 \mu \mathrm{g}$, Novartis Pharma GmbH, Nuernberg, Germany) were added to $249 \mathrm{ml}$ sterile normal saline solution. Each subject received intravenously $1 \mathrm{ml}$ of the solution containing $1 \mu \mathrm{g}$ Synacthen. Individual doses were prepared $10 \mathrm{~min}$ before administration to the subject.

\section{Preparation of the dose of $10 \mu \mathrm{g}$ Synacthen for MDST}

The content of the ampoule with $250 \mu \mathrm{g} / 1 \mathrm{ml}$ ACTH (Synacthen, tetracosactid $250 \mu \mathrm{g}$, Novartis Pharma GmbH, Nuernberg, Germany) was added to $249 \mathrm{ml}$ sterile normal saline solution. Each subject received $10 \mathrm{ml}$ of the solution intravenously containing $10 \mu \mathrm{g}$ Synacthen. Individual doses were prepared $10 \mathrm{~min}$ before administration to the subject.

All of the tests were carried out in a specialized Laboratory for Functional Tests in the Institute of Endocrinology, after overnight fasting between 8-9 a.m. in recumbence position of a subject. After $30 \mathrm{~min}$ of rest in bed with a cannula introduced into the cubital vein, blood samples were collected for the determination of basal plasma hormones (Time 0), and then the dose of Synacthen or insulin was administered intravenously. The next blood samples were taken at 30th, 60th and 90th min after $250 \mu \mathrm{g}, 10 \mu \mathrm{g}$ Synacthen or insulin administration and 30th, 60th min after the administration of $1 \mu \mathrm{g}$ of Synacthen. Thirty minutes after withdrawal of blood samples, they were centrifuged at $3000 \mathrm{rpm}$ for $15 \mathrm{~min}$, and obtained plasma was frozen in plastic tubes and stored at $-20^{\circ} \mathrm{C}$ until analyzed.

A peak plasma cortisol response of greater $500 \mathrm{nmol} / \mathrm{l}$ (Stewart 2001) in each of the test was considered to be normal physiological response. 


\section{Methods for steroid determination}

Cortisol, cortisone, tetrahydrocortisol, allotetrahydrocortisol, tetrahydrocortisone and 6beta-OHcortisol were measured by liquid chromatography-tandem mass spectrometry (LC-MS/MS). Sample processing was completely robotized (Hamilton Robotics, Inc., Reno, NV, USA). Internal standards (cortisol-d4, THE-d5 and THF-d3) were added to $100 \mu \mathrm{l}$ of human EDTA plasma, which was then subjected to liquid-liquid extraction with $480 \mu \mathrm{l}$ of ethylacetate-heptane $\quad(80: 20 ; \quad \mathrm{v}: \mathrm{v})$. The supernatant $(280 \mu \mathrm{l})$ was subsequently washed with sodium hydroxide buffer $(0.1 \mathrm{M})$, evaporated and reconstituted in $100 \mu \mathrm{l}$ of $0.01 \%$ aqueous solution of formic acid:methanol (50:50, v:v). The samples were analyzed on a Waters Acquity UPLC system connected to a Waters Xevo TQ-S tandem mass spectrometer. The compounds were separated on a C-18 BEH phenyl column from Waters $(100 \times 2.1 \mathrm{~mm}$ column, $1.7 \mathrm{~mm}$ particle size, $60{ }^{\circ} \mathrm{C}$ ), which was developed by gradient elution over $5.5 \mathrm{~min}$, using an aqueous solution of formic acid and acetonitrile as mobile phases. Multiple reaction monitoring (MRM) transitions were monitored for formic adducts of cortisol $(409.18 \rightarrow 333.19), \quad$ cortisone (405.22 $\rightarrow 301.24)$, tetra-hydrocortisol $(411.20 \rightarrow 335.20)$, allo-tetrahydrocortisol $\quad(411.20 \rightarrow 335.20), \quad$ tetrahydrocortisone $\quad(409.18 \rightarrow 333.19)$ and 6beta-OH-cortisol $(424.29 \rightarrow 347.20)$, which were detected in negative mode. The range of measurement was $1-200 \mathrm{nM}$ for cortisone, TH cortisone and TH cortisol; 1-1000 nM for cortisol; 6-200 nM for allo TH cortisol and 2-20 nM for 6beta-OH-cortisol.

Accuracies were in the range between 94 and $105 \%$, and imprecision was $<10 \%$ for Cortisol, cortisone, tetrahydrocortisone and 6beta-OH-cortisol and $<12 \%$ tetrahydrocortisol, allo-tetrahydrocortisol.

\section{Statistical analysis}

Respecting the skewed distribution and nonconstant variance in most dependent variables, these were transformed by power transformations to data symmetry and homoscedasticity prior further processing (Meloun et al. 2000). The homogenity and distribution of the transformed data and residuals was checked by residual analysis as described elsewhere (Meloun et al. 2002, 2004). The repeated measurements ANOVA model was used for the evaluation of the relationships between steroid levels, gender, type of test and time after stimulation. The model consisted of subject factor explaining inter-individual variability, between-subject factor Gender (men vs. women), within-subject factors Test (four types of test were investigated in each subject such as HDST, ITT, LDST, and MDST) and Time (times after stimulation 0,30 and $60 \mathrm{~min}$ ), and all corresponding interaction between the factors except of the subject factor. For instance, significant Test $\times$ Time interaction indicates that the type of test significantly influences the course of the time profile (there are significantly different shapes of time profiles between individual tests). F represents the Fisher's statistic and $\mathrm{p}$ designates statistical significance for the factors and interaction. The symbols with error bars represent re-transformed means with their $95 \%$ confidence intervals (triangles, diamonds, squares, and circles symbolize HDST, ITT, LDST, and MDST test, respectively. The full and empty symbols represent men and women, respectively. The $95 \%$ confidence intervals are computed using the least significant difference multiple comparisons $(\mathrm{p}<0.05)$. The confidence intervals, which do not overlap each other, denote significant difference between the respective subgroup means. Statistical software Statgraphics Centurion, version XV from Statpoint Inc. (Herndon, Virginia, USA) was used for the statistical analysis.

\section{Results}

We simultaneously evaluated plasma cortisol, cortisone, THF, THE, all THF and $6 \beta-\mathrm{OHF}$ in the ITT, LDST, HDST and MDST in the same subjects. The results are described in Table 1 and expressed as the means and SD. The cut-off $500 \mathrm{nmol} / 1$ of cortisol was exceeded at 30th min in the HDST, LDST, and MDST, however, in the ITT it was reached with some delay at 60th min. The peaks of all of the hormones were observed at 60th min in the ITT, HSDT, MDST, apart from LDST (Figs 1-6). Levels of cortisol and its metabolites decreased at 60th $\mathrm{min}$ in the LDST. We found significant correlation of cortisol and its metabolites levels at 30th min in the LDST, HDST and MDST.

The ratio of plasma cortisol/cortisone increased in all of the test with a higher degree of interindividual variation; the peak were observed at 60th min in all of the tests excluding the LDST (Fig. 7). 


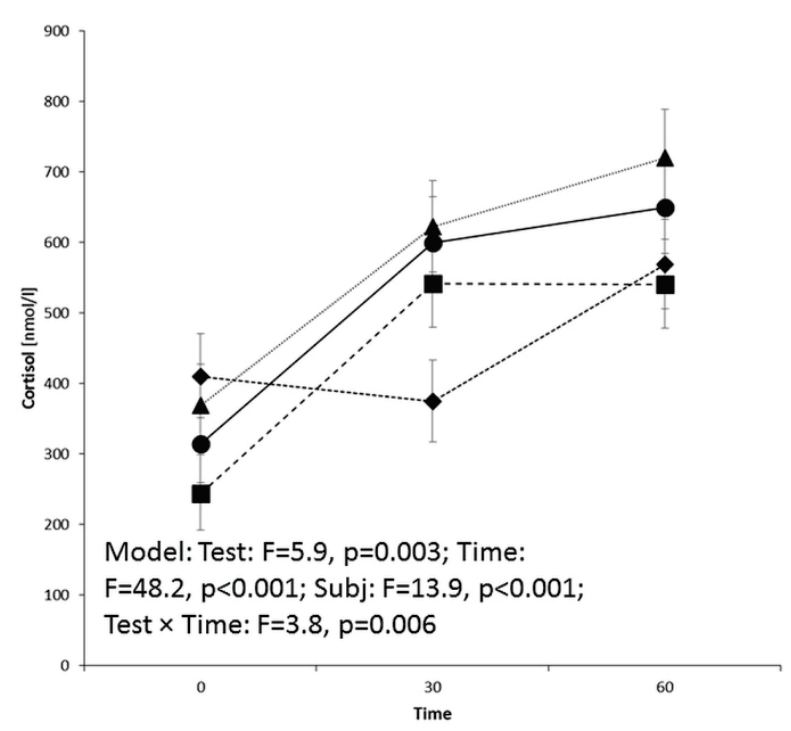

Fig. 1. Different profiles of plasma cortisol for all tests as evaluated using repeated measures ANOVA model. The circles represent MDST, triangles HDST, squares LDST, diamond ITT with error bars represent group means with their $95 \%$ confidence intervals. $\mathrm{F}$ and $\mathrm{p}$ represent the correlation coefficients of the ANOVA model, F-ratio and level of statistical significance.
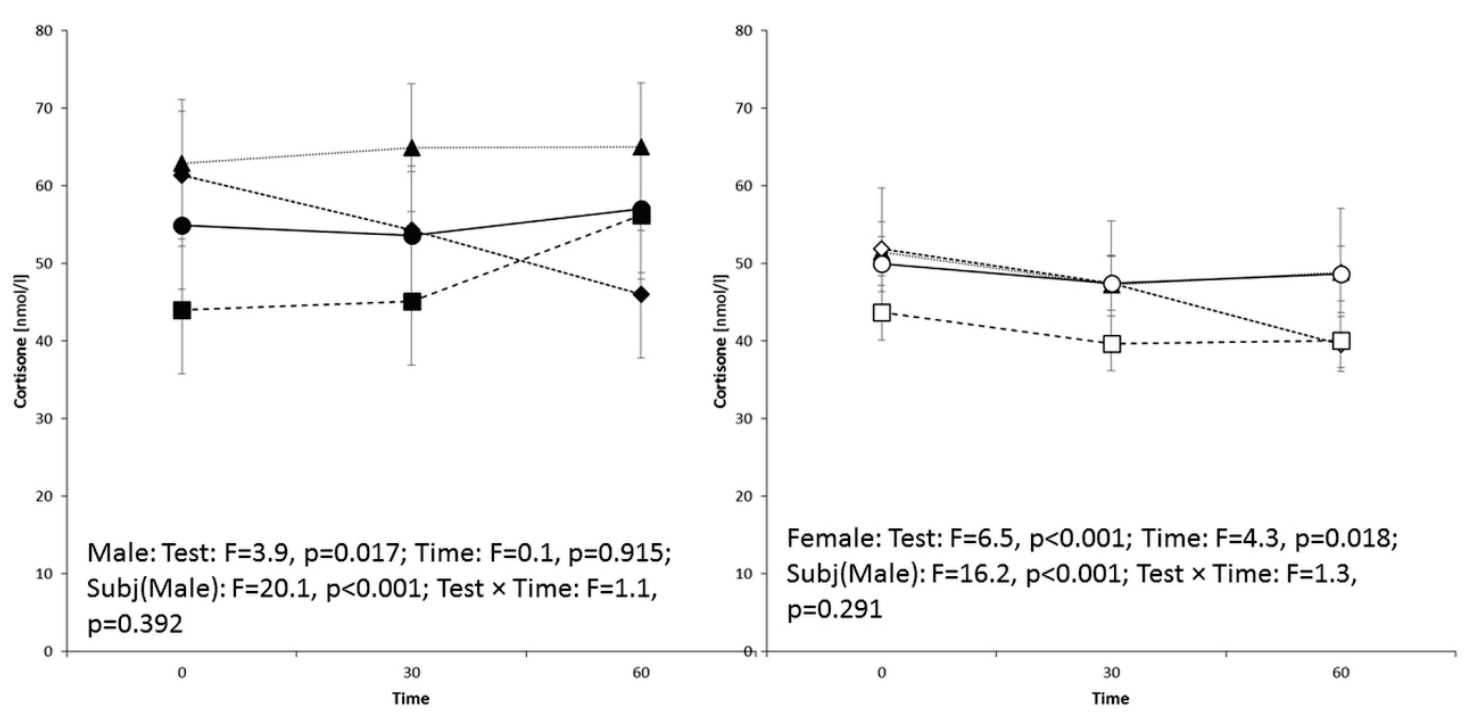

Fig. 2. Different profiles of plasma cortisone for all tests are evaluated using repeated measures ANOVA model. The empty symbols represent female subject and full symbols male subjects, circles represent MDST, triangles HDST, squares LDST, diamond ITT with error bars represent group means with their $95 \%$ confidence intervals. F and p represent the correlation coefficients of the ANOVA model, F-ratio and level of statistical significance.
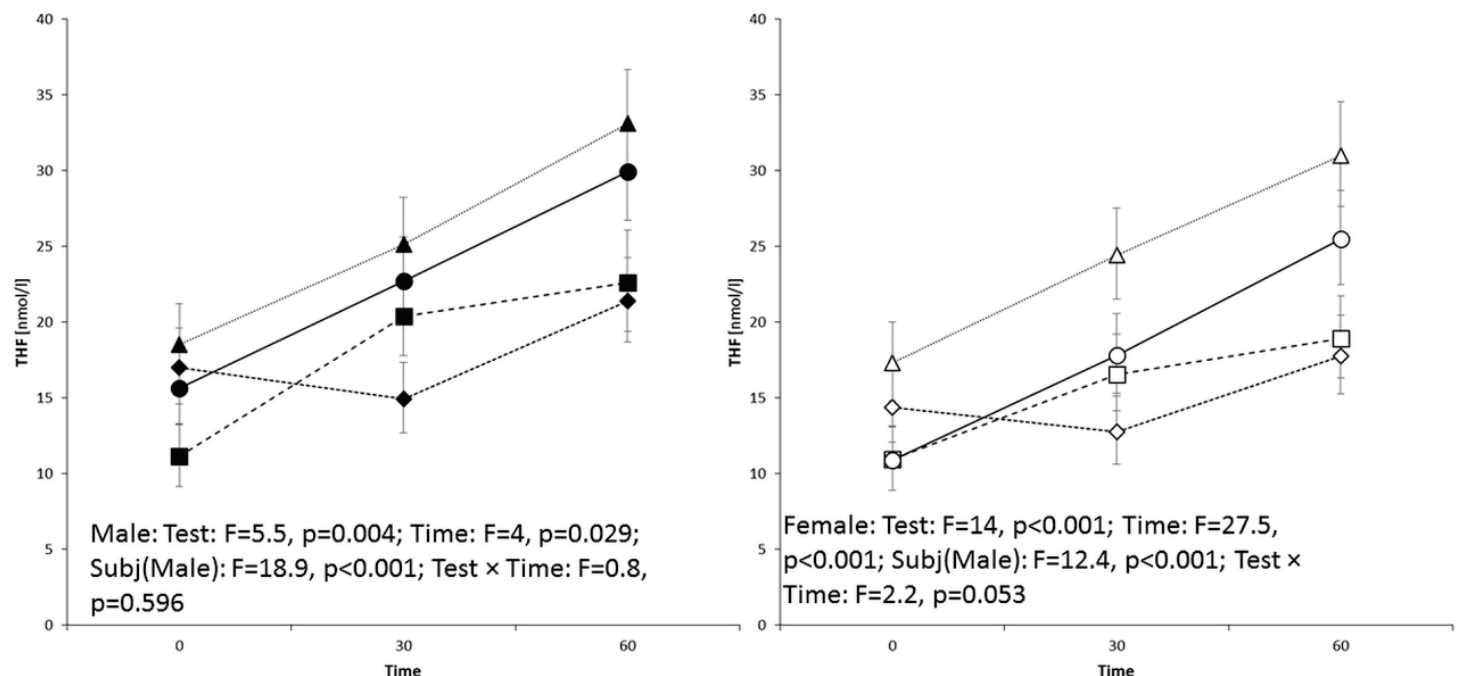

Fig. 3. Different profiles of plasma THF for all tests are evaluated using repeated measures ANOVA model. The empty symbols represent female subject and full symbols male subjects, circles represent MDST, triangles HDST, squares LDST, diamond ITT with error bars represent group means with their $95 \%$ confidence intervals. $\mathrm{F}$ and $\mathrm{p}$ represent the correlation coefficients of the ANOVA model, F-ratio and level of statistical significiance. 


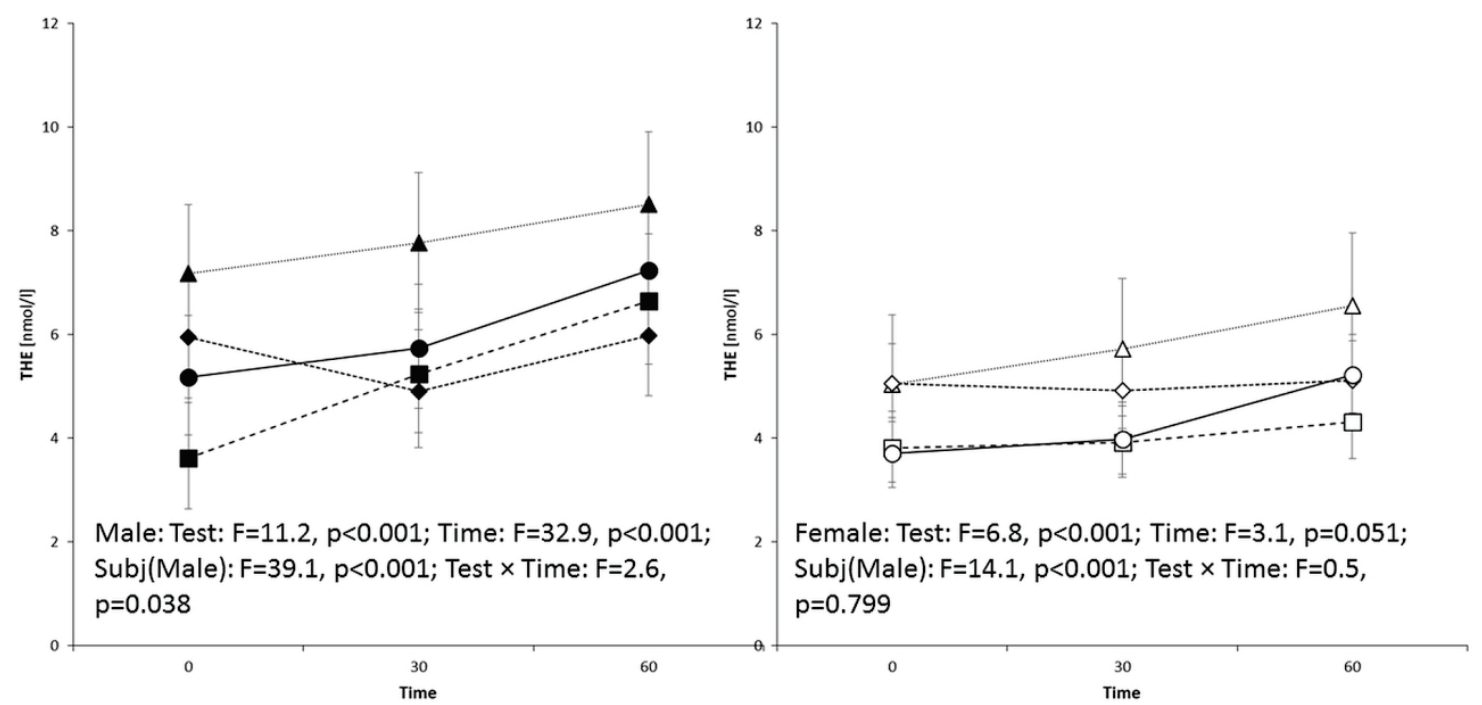

Fig. 4. Different profiles of plasma THE for all tests are evaluated using repeated measures ANOVA model. The empty symbols represent female subject and full symbols male subjects, circles represent MDST, triangles HDST, squares LDST, diamond ITT with error bars represent group means with their $95 \%$ confidence intervals. F and $\mathrm{p}$ represent the correlation coefficients of the ANOVA model, F-ratio and level of statistical significance.

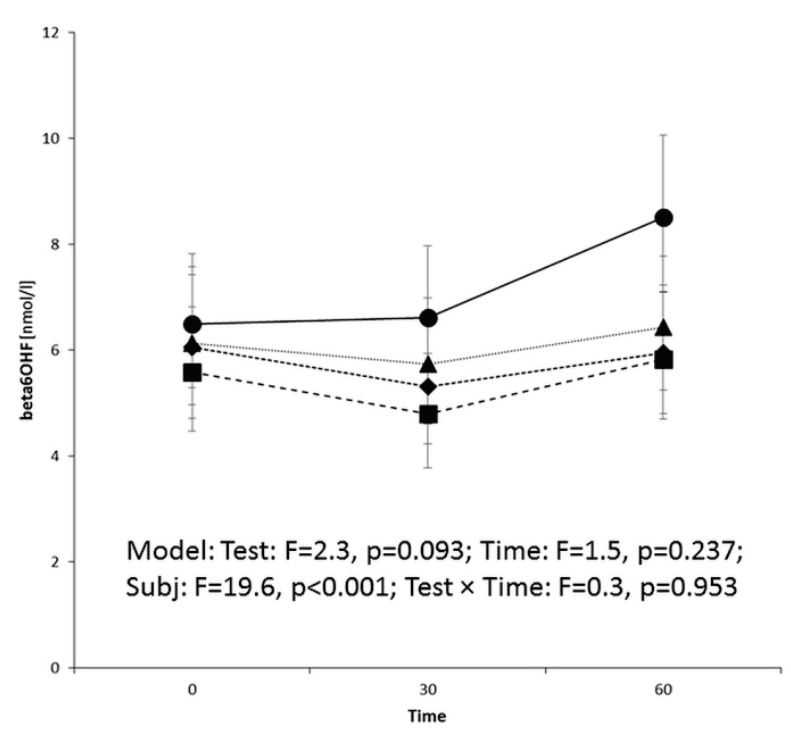

Fig. 5. Different profiles of plasma $6 \beta-O H F$ for all tests as evaluated using repeated measures ANOVA model. The circles represent MDST, triangles HDST, squares LDST, diamond ITT with error bars represent group means with their $95 \%$ confidence intervals. $F$ and $p$ represent the correlation coefficients of the ANOVA model, F-ratio and level of statistical significance.
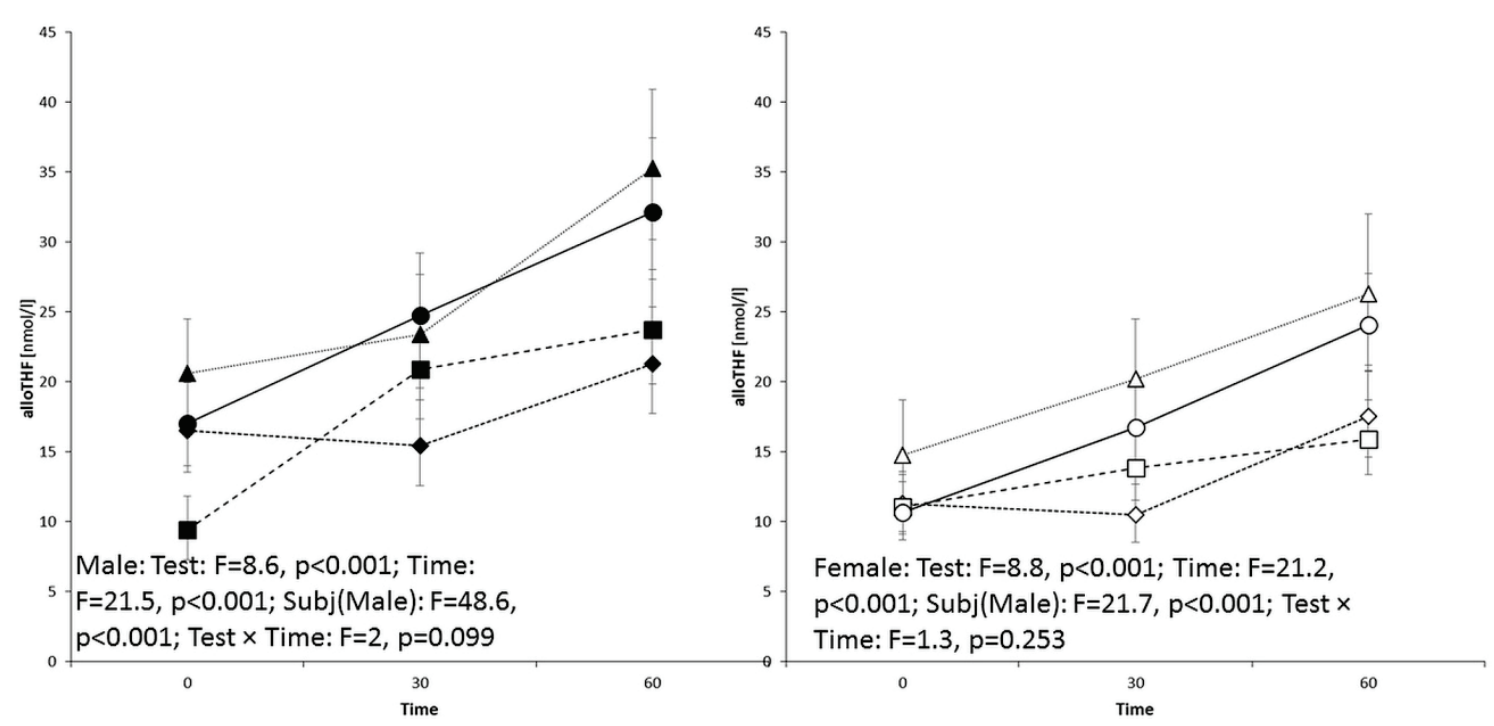

Fig. 6. Different profiles of plasma allo THF for all tests as evaluated using repeated measures ANOVA model. The circles represent MDST, triangles HDST, squares LDST, diamond ITT with error bars represent group means with their $95 \%$ confidence intervals. F and p represent the correlation coefficients of the ANOVA model, F-ratio and level of statistical significance. 

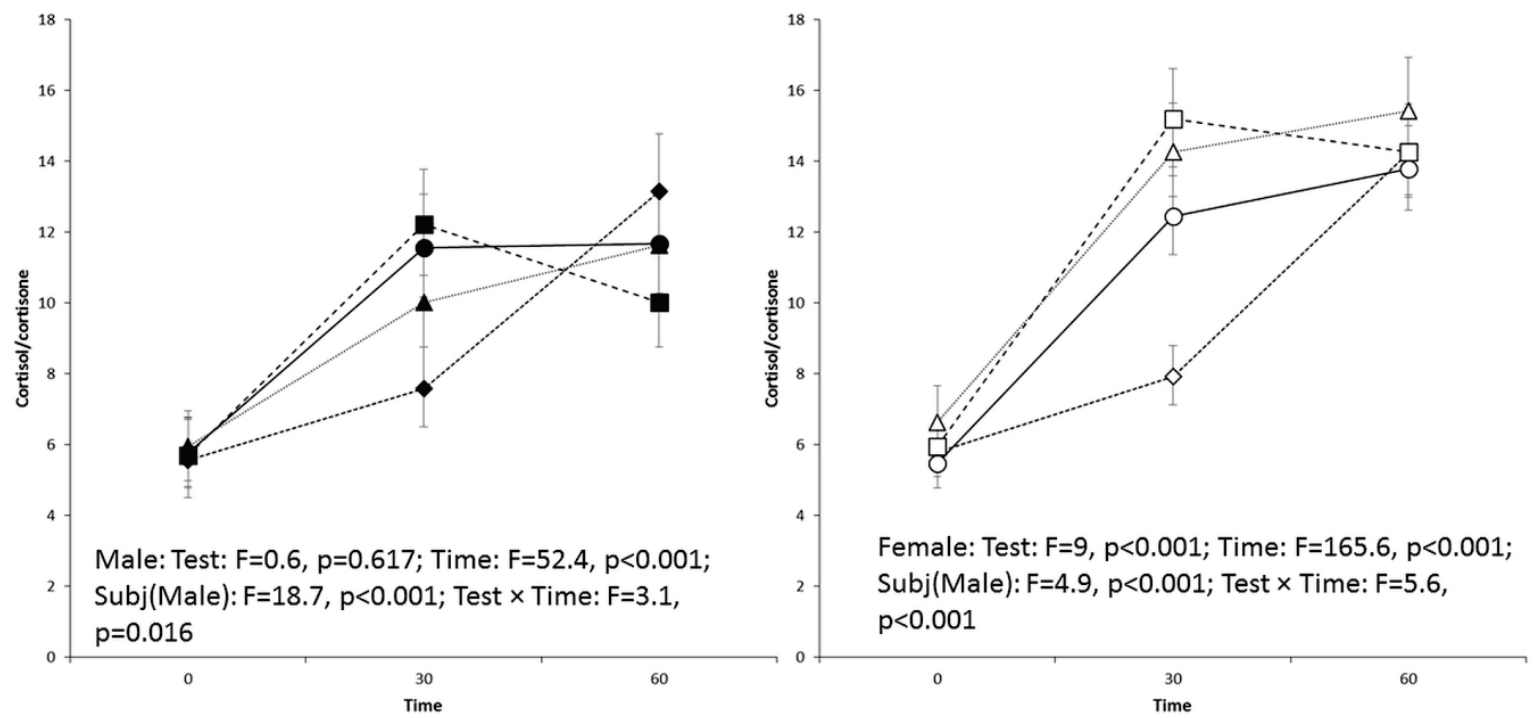

Fig. 7. Different profiles of ration of cortisol/cortisone for all tests as evaluated using repeated measures ANOVA model. The empty symbols represent female subject and full symbols male subjects, circles represent MDST, triangles HDST, squares LDST, diamond ITT with error bars represent group means with their $95 \%$ confidence intervals. $F$ and $p$ represent the correlation coefficients of the ANOVA model, F-ratio and level of statistical significance.

Table 1. The basal and stimulated cortisol and its metabolites in ITT, HDST, MDST and LDST.

\begin{tabular}{lcccccccc}
\hline \multirow{2}{*}{ Variable nmol/l } & \multicolumn{2}{c}{ ITT } & \multicolumn{2}{c}{ HDST } & \multicolumn{2}{c}{ MDST } & \multicolumn{2}{c}{ LDST } \\
\cline { 2 - 9 } & Mean & SD & Mean & SD & Mean & SD & Mean & SD \\
\hline cortisol 0 & 350.40 & 144.10 & 403.10 & 181.30 & 287.60 & 181.30 & 259.10 & 67.60 \\
cortisol 30 & 379.40 & 111.00 & 650.20 & 157.40 & 594.20 & 157.40 & 530.10 & 134.80 \\
cortisol 60 & 578.20 & 142.90 & 739.80 & 122.90 & 661.90 & 122.90 & 486.40 & 148.60 \\
cortisone 0 & 55.40 & 15.80 & 55.60 & 12.90 & 51.80 & 12.90 & 44.10 & 12.10 \\
cortisone 30 & 50.00 & 16.40 & 53.70 & 19.00 & 49.70 & 19.00 & 40.40 & 7.40 \\
cortisone 60 & 42.00 & 10.60 & 54.80 & 17.10 & 51.70 & 17.10 & 45.10 & 11.90 \\
THF 0 & 16.00 & 6.30 & 18.50 & 8.20 & 13.00 & 8.20 & 12.20 & 4.00 \\
THF30 & 14.20 & 6.00 & 25.30 & 7.90 & 20.00 & 7.90 & 19.60 & 6.40 \\
THF60 & 20.00 & 8.00 & 32.10 & 5.90 & 27.70 & 5.90 & 21.80 & 6.70 \\
THE0 & 5.60 & 2.30 & 5.90 & 1.90 & 4.40 & 1.90 & 4.20 & 1.60 \\
THE30 & 5.10 & 2.30 & 6.60 & 2.10 & 4.70 & 2.10 & 5.00 & 1.90 \\
THE60 & 6.50 & 2.40 & 7.30 & 2.00 & 6.10 & 2.00 & 5.70 & 2.20 \\
6ßOHF 0 & 6.90 & 3.80 & 6.20 & 2.10 & 6.40 & 2.00 & 5.00 & 1.90 \\
6ßOHF 30 & 5.70 & 2.70 & 6.20 & 2.40 & 6.50 & 2.30 & 5.30 & 2.10 \\
6ßOHF 60 & 7.60 & 2.90 & 7.50 & 2.50 & 7.90 & 2.40 & 6.00 & 2.60 \\
allo THF 0 & 14.10 & 6.90 & 17.60 & 6.90 & 14.70 & 6.90 & 12.60 & 4.70 \\
allo THF30 & 13.70 & 8.50 & 21.70 & 4.50 & 21.50 & 4.50 & 19.80 & 8.80 \\
allo THF60 & 22.40 & 10.80 & 30.40 & 9.40 & 29.40 & 9.40 & 23.20 & 11.50 \\
cortisole/cortisone 0 & 6.30 & 14.10 & 7.20 & 1.40 & 5.60 & 5.60 & 5.90 & 5.90 \\
cortisole/cortisone 30 & 7.60 & 8.30 & 12.10 & 8.30 & 12.00 & 18.20 & 13.10 & 13.10 \\
cortisole/cortisone 60 & 13.60 & 7.20 & 13.50 & 7.20 & 12.80 & 12.40 & 10.80 & 108.00 \\
\hline
\end{tabular}


The stimulated and baseline levels of cortisol and $6 \beta$-OHF did not differ significantly between female and male subjects, which contrasted with the results for THF, THE, cortisone and cortisol/cortisone ratio. Levels of cortisone and THF, THE, and allo THF were significantly higher in males, whereas the cortisol/ cortisone ratios were higher in females.

The levels of cortisol, cortisone, and THF as well as cortisol/cortisone ratio were significantly lower at 0th and 30th min in the LDST compared to in the other tests, at 60 th $\mathrm{min}$ cortisol reached significantly higher levels in the HDST compare the levels in the ITT. The levels of $6 \beta$-OHF were significantly lower at 60 th $\mathrm{min}$ in the ITT and LDST compared to in the MDST. The levels of the THE were significantly lower at 0th and 30th min in the LDST and MDST compared to the other tests; at 60th min, the THE levels were significantly higher in the HDST compared to in the ITT.

\section{Discussion}

In our study we observed a 2-fold increase in cortisol and cortisone after insulin and Synacthen stimulation, and the highest levels were reached in the HDST at 60 th $\mathrm{min}$. The cut-off of $500 \mathrm{nmol} / 1$ of cortisol was reached in all of the tests, which confirmed the feasibility of the use of the MDST. Additionally, the cortisol metabolites followed the pattern of the cortisol response in all tests.

Several alternative tests for the assessment of the HPA axis have been proposed over the years, but only the Synacthen test has demonstrated good sensitivity and specificity compared with the ITT in many studies (Hurel et al. 1996, Rasmuson et al. 1996, Abdu et al. 1999). Several controversies remain a matter of debate when using the Synacthen test to evaluate the HPA axis. The most discussed issue is the dose of Synacthen. The use of $1 \mu \mathrm{g}, 12.5 \mu \mathrm{g}$ and $25 \mu \mathrm{g}$ instead of standard $250 \mu \mathrm{g}$ of Synacthen has been suggested (Contreras et al. 2004, Dorin et al. 2003, Agha et al. 2006, Abdu et al. 1999). The LDST test showed a similar maximal response of cortisol in 30th min, which corresponded to cortisol response in HDST and ITT (Nye et al. 1999). With respect to the timing of blood tests after stimulation, the time of occurrence of maximal stimulation levels and of achievement of cut-off for cortisol have been published in more than 100 studies, yet clear consensus is still lacking (Deutschbein et al. 2009, Daidoh et al. 1995). Moreover, the maximal level of cortisol may vary and may also differ between secondary and primary adrenal insufficiency (Tordjman et al. 2000, Rasmuson et al. 1996). Studies comparing the ITT and the Synacthen tests showed good correlation, but the time at which maximal cortisol response was detected strongly depended on the Synacthen dose (Gonzalbez et al. 2000). In our study, the level of cortisol also depended on the administered dose of Synacthen and continued to increase, reaching the maximum at 60th $\mathrm{min}$ in the HDST and MDST. In contrast, the peak of cortisol in the LDST was reached at 30th min, and at 60th min, the levels of cortisol did not correlate with those in either the HDST or MDST. Early termination of the LDST test can contribute to a higher number of false positive results and $11 \%$ of patients may be misdiagnosed (Karaca et al. 2011). This may be avoided thought the use of $10 \mu \mathrm{g}$ of Synacthen. Futhermore, aside from methodological issues, errors in the pre-analytic phase may also contribute to the variability in the response of cortisol to Synacthen. In particular, the stability of Synacthen after it is reconstituted and the method of reconstitution may play a role (Hana et al. 2015). Therefore, we introduced a $10 \mu \mathrm{g}$ dose of Synacthen. The stability of $1 \mu \mathrm{g}$ Synacthen for up to 30 days in storage has been recently demonstrated (Ananthanraman et al. 2015). We observed an excellent correlation between the results in the HDST and ITT at 30th and 60th min after Synacthen administration, and the maximum cortisol response that was observed at 60th min in ITT and HDST as well as MDST. That shows applicability of MDST test. The supraphysiological dose of $250 \mu \mathrm{g}$ of Synacthen causes prolonged production of cortisol to $90 \mathrm{~min}$ after the Synacthen administration (Dickstein et al. 1991). We also observed an ongoing increase of cortisol at 60th min in the MDST test. This result indicates that medium dose of $10 \mu \mathrm{g}$ of Synacthen is still a supraphysiological dose. Further comparative studies among ITT, HDST and MDST may be of importance.

The cortisol metabolites THF and allo THF followed the same pattern as the response of cortisol. In contrast, the cortisone metabolites either decreased at 30 th $\min$ and recovered at 60 th $\min$ or remained unchanged. The ratio of cortisol/cortisone increased and reached twice its basal level, which is in agreement with previous findings (Vogesel et al. 2001). Those findings correspond to the shift to the conversion of cortisone to cortisol, which increase the levels of biologically active hormone.

Stimulation of the HPA axis induced remarkable 
increases in the cortisol/cortisone ratio and also significant increases in the levels of THF, allo THF and $6 \beta-\mathrm{OHF}$, which are steroids known as neuro-active compounds. It is possible that stimulation of adrenal cortisol secretion also directly influences the activity of $11 \beta$-HSD. $11 \beta$-HSD1 is a ubiquitous enzyme that predominantly acts as an oxoreductase and converts cortisone to cortisol. Hepatocytes and adipocytes are the major source of that conversion, many factors, such as hormones of adipose tissue regulate the activity of this enzyme (Morgan et al. 2014). Recent studies have shown the important role of $11 \beta$-HSD1 in the development of insulin resistance (Morgan et al. 2009). The activity of 11 $\beta$-HSD1 may be altered by several conditions, e.g. obesity, and may determine the degree of cortisol regeneration. This is important particularly in critically ill patients and for glucocorticoid replacement treatment (Boonen and van den Berghe 2014). Another explanation is that rapid cortisol secretion supplies the circulation with an amount of the active steroid, that the steroid metabolising enzymes are unable adequately metabolise in time because the half-life of cortisol is $40 \mathrm{~min}$ (Kraan et al. 1997). Thus, a limitation of the study may be the short period of follow up after Synacthen stimulation.

Gender also plays an important role in the regulation of $11 \beta$-HSD1 activity. Estradiol has been suggested to inhibit hepatic 11 $\beta$-HSD1-mediated reduction of cortisone, but after adjusting for BMI, the estradiol effect disappeared; thus, other factors may play an important role in $11 \beta$-HSD1 regulation. Further studies in mice confirmed that the activity of liver $11 \beta$-HSD1 was lower in female mice and depended on body mass index (Mattson et al. 2012, Low et al. 1994). This may explain the gender difference in cortisone levels in our study because BMI was similar in both groups.

In conclusion, we observed a similar response of cortisol and its metabolites after 3 different doses of Synacthen test and in the ITT. These results suggest that a test with $10 \mu \mathrm{g}$ of Synacthen may be an option to replace the ITT and the HDST test, but further confirmation is essential.

\section{Conflict of Interest}

There is no conflict of interest.

\section{Acknowledgements}

We thank the study participants and research nurses at Institute of Endocrinology. The study was supported by grant NT 11 277-6 of the Internal Grant Agency of the Ministry of Health of the Czech Republic (IGA MZCR).

\section{References}

ABDU TA, ELHADD TA, NEARY R, CLAYTON RN: Comparison of the low dose short synacthen test (1 microg), the conventional dose short synacthen test (250 microg), and the insulin tolerance test for assessment of the hypothalamo-pituitary-adrenal axis in patients with pituitary disease. J Clin Endocrinol Metab 84: 838-843, 1999.

AGHA A, TOMLINSON JW, CLARK PM, HOLDER G, STEWART PM: The long-term predictive accuracy of the short synacthen (corticotropin) stimulation test for assessment of the hypothalamic-pituitary-adrenal axis. J Clin Endocrinol Metab 91: 43-47, 2006.

ANANTHARAMAN R, MENEZES G, YUSUF R, GANAPATHI B, AYYAR SV, SRINIVASAN R: The $1 \mu \mathrm{g}$ cosyntropin test in normal individuals: A reappraisal. Indian J Endocrinol Metab 17: 693-936, 2013.

BOONEN E, VAN DEN BERGHE G: Cortisol metabolism in critical illness: implications for clinical care. Curr Opin Endocrinol Diabetes Obes 21: 185-192, 2014.

CONTRERAS LN, ARREGGER AL, PERSI GG, GONZALEZ NS, CARDOSO EM: A new less-invasive and more informative low-dose ACTH test: salivary steroids in response to intramuscular corticotrophin. Clin Endocrinol (Oxf) 61: 675-682, 2004.

DAIDOH H, MORITA H, MUNE T, MURAYAMA M, HANAFUSA J, NI H, SHIBATA H, YASUDA K: Responses of plasma adrenocortical steroids to low dose ACTH in normal subjects. Clin Endocrinol (Oxf) 43: 311-315, 1995.

DEUTSCHBEIN T, UNGER N, MANN K, PETERSENN S: Diagnosis of secondary adrenal insufficiency in patients with hypothalamic-pituitary disease: comparison between serum and salivary cortisol during the high-dose short synacthen test. Eur J Endocrinol 160: 9-16, 1999. 
DICKSTEIN G: The assessment of the hypothalamo-pituitary-adrenal axis in pituitary disease: are there short cuts? J Endocrinol Invest 26: 25-30, 2003.

DICKSTEIN G, SHECHNER C, NICHOLSON WE, ROSNER I, SHEN-ORR Z, ADAWI F, LAHAV M: Adrenocorticotropin stimulation test: effects of basal cortisol level, time of day, and suggested new sensitive low dose test. J Clin Endocrinol Metab 72: 773-778, 1991.

DORIN RI, QUALLS CR, CRAPO LM: Diagnosis of adrenal insufficiency. Ann Intern Med 139: 194-204, 2003.

DÖTSCH J, DÖRR HG, STALLA GK, SIPPELL WG: Effect of glucocorticoid excess on the cortisol/cortisone ratio. Steroids 66: 817-820, 2001.

GOMES-SANTOS E, SALVATORI R, FERRÃO TO, OLIVEIRA CR, DINIZ RD, SANTANA JA, PEREIRA FA, BARBOSA RA, SOUZA AH, MELO EV, EPITÁCIO-PEREIRA CC, OLIVEIRA-SANTOS AA, OLIVEIRA IA, MACHADO JA, SANTANA-JÚNIOR FJ, BARRETO-FILHO JA, AGUIAR-OLIVEIRA MH: Increased visceral adiposity and cortisol to cortisone ratio in adults with congenital lifetime isolated GH deficiency. J Clin Endocrinol Metab 99: 3285-3289, 2014.

GONZÁLBEZ J, VILLABONA C, RAMÓN J, NAVARRO MA, GIMÉNEZ O, RICART W, SOLER J: Establishment of reference values for standard dose short synacthen test (250 microgram), low dose short synacthen test (1 microgram) and insulin tolerance test for assessment of the hypothalamo-pituitary-adrenal axis in normal subjects. Clin Endocrinol (Oxf) 53: 199-204, 2000.

HÁNA V JR, JEŽKOVÁ J, KOSÁK M, KRŠEK M, MAREK J, NETUKA D, HILL M, HÁNA V: Prediction of adrenocortical insufficiency after pituitary adenoma surgery using postoperative basal cortisol levels. Physiol Res 64: 531-536, 2015.

HUGHES KA, MANOLOPOULOS KN, IQBAL J, CRUDEN NL, STIMSON RH, REYNOLDS RM, NEWBY DE, ANDREW R, KARPE F, WALKER BR: Recycling between cortisol and cortisone in human splanchnic, subcutaneous adipose, and skeletal muscle tissues in vivo. Diabetes 61: 1357-1364, 2012.

HUREL SJ, THOMPSON CJ, WATSON MJ, HARRIS MM, BAYLIS PH, KENDALL-TAYLOR P: The short Synacthen and insulin stress tests in the assessment of the hypothalamic-pituitary-adrenal axis. Clin Endocrinol (Oxf) 44: 141-146, 1996.

KARACA Z, LALE A, TANRIVERDI F, KULA M, UNLUHIZARCI K, KELESTIMUR F: The comparison of low and standard dose ACTH and glucagon stimulation tests in the evaluation of hypothalamo-pituitary-adrenal axis in healthy adults. Pituitary 14: 134-140, 2011.

KRAAN GP, DULLAART RP, PRATT JJ, WOLTHERS BG, DE BRUIN R: Kinetics of intravenously dosed cortisol in four men. Consequences for calculation of the plasma cortisol production rate. J Steroid Biochem Mol Biol 63: 139-146, 1997.

LARSEN PR, KRONENBERG HM, MELMED S, POLONSKY KS: Williams Textbook of Edocrinology. Saunders, Philadelphia, 2002.

LOW SC, CHAPMAN KE, EDWARDS CR, WELLS T, ROBINSON IC, SECKL JR: Sexual dimorphism of hepatic 11 beta-hydroxysteroid dehydrogenase in the rat: the role of growth hormone patterns. $J$ Endocrinol 143: 541-548, 1994.

MATTSSON C, RASK E, CARLSTRÖM K, ANDERSSON J, ELIASSON M, AHRÉN B, SÖDERBERG S, OLSSON T: Gender-specific links between hepatic 11beta reduction of cortisone and adipokines. Obesity (Silver Spring) 15: 887-894, 2007.

MELOUN M, HILL M, MILITKY J, KUPKA K: Transformation in the PC-aided biochemical data analysis. Clin Chem Lab Med 38: 553-559, 2000.

MELOUN M, MILITKY J, HILL M, BRERETON RG: Crucial problems in regression modelling and their solutions. Analyst 127: 433-450, 2002.

MELOUN M, HILL M, MILITKY J, VRBIKOVA J, STANICKA S, SKRHA J: New methodology of influential point detection in regression model building for the prediction of metabolic clearance rate of glucose. Clin Chem Lab Med 42: 311-322, 2004.

METHLIE P, HUSTAD SS, KELLMANN R, ALMÅS B, ERICHSEN MM, HUSEBYE E, LØVÅS K: Multisteroid LC-MS/MS assay for glucocorticoids and androgens, and its application in Addison's disease. Endocr Connect 2: 125-136, 2014. 
MORGAN SA, SHERLOCK M, GATHERCOLE LL, LAVERY GG, LENAGHAN C, BUJALSKA IJ, LABER D, YU A, CONVEY G, MAYERS R, HEGYI K, SETHI JK, STEWART PM, SMITH DM, TOMLINSON JW: 11 beta-hydroxysteroid dehydrogenase type 1 regulates glucocorticoid-induced insulin resistance in skeletal muscle. Diabetes 58: 2506-2515, 2009.

MORGAN SA, MCCABE EL, GATHERCOLE LL, HASSAN-SMITH ZK, LARNER DP, BUJALSKA IJ, STEWART PM, TOMLINSON JW, LAVERY GG: $11 \beta$-HSD1 is the major regulator of the tissue-specific effects of circulating glucocorticoid excess. Proc Natl Acad Sci U S A 111: E2482-E2491, 2014.

NIXON M, WAKE DJ, LIVINGSTONE DE, STIMSON RH, ESTEVES CL, SECKL JR, CHAPMAN KE, ANDREW R, WALKER BR: Salicylate downregulates 11 $\beta$-HSD1 expression in adipose tissue in obese mice and in humans, mediating insulin sensitization. Diabetes 61: 790-796, 2012.

NYE EJ, GRICE JE, HOCKINGS GI, STRAKOSCH CR, CROSBIE GV, WALTERS MM: Comparison ofadrenocorticotropin $(\mathrm{ACTH})$ stimulation tests and insulin hypoglycemia in normal humans: Low dose, standard high dose, and 8-hour ACTH-(1-24) infusion tests. J Clin Endocrinol Metab 84: 3648-3655, 1999.

RASMUSON S, OLSSON T, HAGG E: A low dose ACTH test to assess the function of the hypothalamic-pituitaryadrenal axis. Clin Endocrinol (Oxf) 44: 151-156, 1996.

STEWART PM, TOOGOOD AA, TOMLINSON JW: Growth hormone, insulin-like growth factor-1 and the cortisolcortisone shuttle. Horm Res 56 (Suppl 1): 1-6, 2001.

TORDJMAN K, JAFFE A, TROSTANETSKY Y, GREENMAN Y, LIMOR R, STERN N: Low-dose (1 microgram) adrenocorticotrophin (ACTH) stimulation as a screening test for impaired hypothalamo-pituitary-adrenal axis function: sensitivity, specificity and accuracy in comparison with the high-dose (250 microgram) test. Clin Endocrinol (Oxf) 52: 633-640, 2000.

VOGESER M, ZACHOVAL R, JACOB K: Serum cortisol/cortisone ratio after Synacthen stimulation. Clin Biochem 34: 421-425, 2001.

WILLENBERG HS, MANSMANN G, FRITZEN R, SCHOTT M, FELDKAMP J, SCHULTE HM, SCHERBAUM WA, BORNSTEIN SR: The short synacthen test in the evaluation of adrenal masses in patients with malignancies. Endocr Res 28: 793-797, 2002. 